\title{
Phase 1 study of sirolimus in combination with oral cyclophosphamide and topotecan in children and young adults with relapsed and refractory solid tumors
}

\author{
Kieuhoa T. Vo ${ }^{1}$, Erin E. Karski ${ }^{1}$, Nicole M. Nasholm ${ }^{1}$, Shelly Allen ${ }^{1}$, Fabienne \\ Hollinger $^{1}$, W. Clay Gustafson ${ }^{1}$, Janel R. Long-Boyle ${ }^{2}$, Stephen Shiboski ${ }^{3}$, Katherine \\ K. Matthay ${ }^{1}$ and Steven G. DuBois ${ }^{1}$ \\ ${ }^{1}$ Department of Pediatrics, UCSF Benioff Children's Hospital, University of California, San Francisco School of Medicine, San \\ Francisco, CA, USA \\ 2 Department of Clinical Pharmacy, UCSF Benioff Children's Hospital, University of California, San Francisco School of \\ Medicine, San Francisco, CA, USA \\ ${ }^{3}$ Department of Epidemiology and Biostatistics, UCSF Benioff Children's Hospital, University of California, San Francisco \\ School of Medicine, San Francisco, CA, USA
}

Correspondence to: Kieuhoa T. Vo, email: kieuhoa.vo@ucsf.edu

Keywords: phase 1, mTOR, sirolimus, topotecan, cyclophosphamide

Received: August 23, $2016 \quad$ Accepted: October 13, $2016 \quad$ Published: October 25, 2016

\section{ABSTRACT}

Purpose: To determine the maximum tolerated dose (MTD), toxicities, and pharmacodynamics effects of sirolimus combined with oral metronomic topotecan and cyclophosphamide in a pediatric population.

Materials and Methods: Patients who were 1 to 30 years of age with relapsed/ refractory solid tumors (including CNS) were eligible. Patients received daily oral sirolimus and cyclophosphamide $\left(25-50 \mathrm{mg} / \mathrm{m}^{2} / \mathrm{dose}\right)$ on days $1-21$ and oral topotecan $\left(0.8 \mathrm{mg} / \mathrm{m}^{2} /\right.$ dose $)$ on days $1-14$ in 28 -day cycles. Sirolimus steady-state plasma trough concentrations of 3-7.9 $\mathrm{ng} / \mathrm{mL}$ and 8-12.0 $\mathrm{ng} / \mathrm{mL}$ were evaluated, with dose escalation based on a $3+3$ phase 1 design. Biomarkers of angiogenesis were also evaluated.

Results: Twenty-one patients were treated (median age 18 years; range 9-30). Dose-limiting toxicities included myelosuppression, ALT elevation, stomatitis, and hypertriglyceridemia. The MTD was sirolimus with trough goal of 8-12.0 ng/ $\mathrm{mL}$; cyclophosphamide $25 \mathrm{mg} / \mathrm{m}^{2} /$ dose; and topotecan $0.8 \mathrm{mg} / \mathrm{m}^{2} /$ dose. No objective responses were observed. Four patients had prolonged stable disease $>$ 4 cycles (range 4-12). Correlative biomarker analyses demonstrated reductions in thrombospondin-1 $(p=0.043)$ and soluble vascular endothelial growth factor receptor-2 plasma concentrations at 21 days compared to baseline.

Conclusions: The combination of oral sirolimus, topotecan, and cyclophosphamide was well tolerated and biomarker studies demonstrated modulation of angiogenic pathways with this regimen.

\section{INTRODUCTION}

The mammalian target of rapamycin (mTOR) is a ubiquitous serine threonine kinase that is involved in the regulation of cell cycle, angiogenesis and apoptosis. [1] Sirolimus (also known as rapamycin) is an mTOR inhibitor originally approved for immunosuppression in patients who received renal transplants. [1] More recently, the mTOR pathway has been shown to be upregulated in many pediatric solid tumors. [2, 3] As such, mTOR inhibitors have been investigated in preclinical and clinical studies of childhood cancer. In murine models, single agent sirolimus has been shown to inhibit tumor growth in vivo in rhabdomyosarcoma, Ewing sarcoma, medulloblastoma, glioblastoma, neuroblastoma, and osteosarcoma. [4-7] Preclinical trials looking at the combination of sirolimus and cyclophosphamide have also revealed therapeutic enhancement in xenograft models of 
Table 1: Patient characteristics

\begin{tabular}{|l|l|}
\hline & $\begin{array}{l}\text { All Patients } \\
(\mathbf{N = 2 1})\end{array}$ \\
\hline Median age, years (range) & $18(9-30)$ \\
\hline Male:Female & $15: 6$ \\
\hline Diagnosis & \\
\hline Osteosarcoma & 7 \\
\hline Ewing sarcoma & 3 \\
\hline Rhabdomyosarcoma & 3 \\
\hline Brain Tumor & $2^{\mathrm{a}}$ \\
\hline Neuroblastoma & 1 \\
\hline Other & $5^{\mathrm{b}}$ \\
\hline Disease Status & \\
\hline Measurable by RECIST & $21(100 \%)$ \\
\hline Prior Therapy & \\
\hline mTOR Inhibitor & $1(5 \%)$ \\
\hline Cyclophosphamide & $9(43 \%)$ \\
\hline Topotecan & $7(33 \%)$ \\
\hline
\end{tabular}

${ }^{a}$ One patient each with medulloblastoma and glioblastoma multiforme.

${ }^{\mathrm{b}}$ One patient each with alveolar soft part sarcoma, desmosplastic small round cell tumor, esthesioneuroblastoma, myxofibrosarcoma, and undifferentiated sarcoma.

pediatric solid tumors suggesting that mTOR inhibitors have the potential to augment the activity of conventional chemotherapy drugs. [8] Indeed, a recent clinical trial in pediatric patients with relapsed rhabdomyosarcoma demonstrated benefit of the combination of temsirolimus, vinorelbine, and cyclophosphamide. [9] In addition to direct effects on tumor cells, sirolimus has also been shown to reduce tumor angiogenesis. $[7,10,11]$

Intravenous preparations of topotecan and cyclophosphamide have been shown to be active in pediatric solid tumors, particularly Ewing sarcoma, neuroblastoma, and rhabdomyosarcoma. [12-16] Historically, this chemotherapy combination has been administered in pulses at 3-4 week intervals. However, recent data suggest that relatively low-dose, continuous chemotherapy ("metronomic") administered over prolonged periods may be effective as well. [17] This approach has been hypothesized to work by targeting endothelial cells and thus providing a form of antiangiogenic therapy. [17] Phase 1 trials of oral cyclophosphamide and topotecan have been well tolerated when given in a continuous low-dose or "metronomic" schedule, with myelosuppression being dose limiting. [18]

The current report describes the results of a pediatric phase 1 study of sirolimus administered in combination with oral topotecan and cyclophosphamide to children and young adults with refractory or recurrent solid tumors. We pursued this combination based upon preclinical data demonstrating additive activity of sirolimus in combination with chemotherapy, the antiangiogenic properties associated with both metronomic chemotherapy and mTOR inhibition, and a desire to develop a fully oral combination for patients with advanced cancer who prefer to be treated largely at home. The primary aims of the study were to describe the toxicities and to recommend a phase 2 trough concentration of sirolimus when administered on a protracted schedule in combination with oral topotecan and cyclophosphamide. Secondary endpoints included an assessment of antitumor activity and pharmacodynamic markers of antiangiogenic effect.

\section{RESULTS}

\section{Patient characteristics}

Characteristics of the 21 enrolled patients are shown in Table 1. All patients had measurable disease by Response Evaluation Criteria in Solid Tumors (RECIST). One patient had received previous therapy with another mTOR inhibitor, ridaforolimus. The number of prior therapy regimens for study subjects are shown in Table 2 . In the heavily pretreated cohort, patients received a median of 3 prior treatment regimens (range, 2 to 13). Patients received a median of 1 cycle (range, 1 to 12) of protocol therapy (Table 2).

\section{Dose escalation and toxicity}

Dose escalation and observed dose-limiting toxicities (DLTs) are summarized in Table 2. Three patients were enrolled and evaluable on dose level 1, none of whom had first cycle DLT. Eight patients were 
Table 2: Summary of prior treatment regimens, dose escalation, and dose-limiting toxicities (DLT)

\begin{tabular}{|c|c|c|c|c|c|}
\hline Subject ID & \begin{tabular}{|l|l|}
$\begin{array}{l}\text { Number of } \\
\text { Regimens }\end{array}$ & Prior \\
\end{tabular} & \begin{tabular}{|l|}
$\begin{array}{l}\text { Evaluable for Cycle 1 } \\
\text { DLT? }\end{array}$ \\
\end{tabular} & Cycle 1 DLT? & $\begin{array}{|lll|}\begin{array}{l}\text { Number } \\
\text { Received }\end{array} & \text { of } & \text { Cycles } \\
\end{array}$ & Description of DLT \\
\hline \multicolumn{6}{|c|}{ Dose Level 1: sirolimus goal 3-7.9 ng/mL; cyclophosphamide $25 \mathrm{mg} / \mathrm{m}^{2}$; topotecan $0.8 \mathrm{mg} / \mathrm{m}^{2}$} \\
\hline 01 & 11 & Yes & No & 1 & \\
\hline 02 & 3 & Yes & No & 11 & \\
\hline 03 & 2 & Yes & No & 1 & \\
\hline \multicolumn{6}{|c|}{ Dose Level 2: sirolimus goal 8-12 ng/mL; cyclophosphamide $25 \mathrm{mg} / \mathrm{m}^{2}$; topotecan $0.8 \mathrm{mg} / \mathrm{m}^{2}$} \\
\hline 04 & 2 & Yes & Yes & 1 & $\begin{array}{l}\text { Cycle 1 DLT, prolonged } \\
\text { thrombocytopenia }\end{array}$ \\
\hline 05 & 4 & $\mathrm{No}^{\mathrm{a}}$ & No & 1 & \\
\hline 06 & 6 & $\mathrm{No}^{\mathrm{b}}$ & No & & \\
\hline 07 & 4 & Yes & No & 12 & \begin{tabular}{|lr} 
Subsequent & cycle \\
DLT, grade & 4 \\
hypertriglyceridemia
\end{tabular} \\
\hline 08 & 3 & Yes & No & 1 & \\
\hline 09 & 8 & Yes & No & 4 & $\begin{array}{l}\text { Subsequent cycle DLT, } \\
\text { grade } 3 \text { stomatitis }\end{array}$ \\
\hline 10 & 3 & Yes & No & 6 & \\
\hline 11 & 3 & Yes & No & 1 & \\
\hline \multicolumn{6}{|c|}{ Dose Level 3: sirolimus goal 8-12 ng/mL; cyclophosphamide $50 \mathrm{mg} / \mathrm{m}^{2}$; topotecan $0.8 \mathrm{mg} / \mathrm{m}^{2}$} \\
\hline 12 & Unknown & \begin{tabular}{|l|} 
Yes \\
\end{tabular} & No & 1 & \\
\hline 13 & 3 & Yes & No & 1 & \\
\hline 14 & 2 & Yes & Yes & 1 & $\begin{array}{l}\text { Cycle } 1 \text { DLT, prolonged } \\
\text { ALT elevation }\end{array}$ \\
\hline 15 & 3 & $\mathrm{No}^{\mathrm{c}}$ & No & 1 & \\
\hline 16 & 3 & $\mathrm{No}^{\mathrm{d}}$ & $\mathrm{No}^{\mathrm{d}}$ & 1 & \\
\hline 17 & 13 & $\mathrm{No}^{\mathrm{a}}$ & No & 1 & \\
\hline 18 & 6 & $\mathrm{No}^{\mathrm{a}}$ & No & 2 & \\
\hline 19 & 8 & $\mathrm{No}^{\mathrm{a}}$ & No & 1 & \\
\hline 20 & 5 & Yes & Yes & 3 & $\begin{array}{l}\text { Cycle 1 DLT, prolonged } \\
\text { neutropenia }\end{array}$ \\
\hline 21 & 2 & $\mathrm{No}^{\mathrm{c}}$ & No & 1 & \\
\hline
\end{tabular}

a Sirolimus trough level not in range within 12 days of beginning protocol therapy.

${ }^{\mathrm{b}}$ Patient withdrew consent after the first day of protocol therapy.

c Patient off study due to early progression in cycle 1.

d Patient missed labs to document timely count recovery, cannot exclude DLT.

subsequently enrolled on dose level 2, two of whom were not evaluable for DLT. One patient withdrew consent after the first day of protocol therapy and the second patient did not reach sirolimus goal trough by day 12 of cycle 1. Of the six patients evaluable for DLT in dose level 2, one patient developed dose-limiting prolonged thrombocytopenia during cycle 1 . With 1 of 6 patients with first cycle DLT at dose level 2, dose level 3 was then evaluated. Ten patients were enrolled on dose level 3 , six of whom were not evaluable for DLT. Three patients had delays in reaching target sirolimus trough levels, two patients had early disease progression during cycle 1 , and one patient had grade 4 thrombocytopenia during cycle 1 and declined appropriate laboratory studies to document recovery within 2 weeks of planned start of cycle 2 (patient subsequently went off study due to disease progression). Of the remaining four patients evaluable for DLT in dose level 3, two patients had first cycle DLT (grade 2 ALT elevation that did not resolve within 14 days; grade 4 neutropenia $>7$ days). These results established that dose level 3 was not tolerable and the maximum tolerated dose (MTD) was determined to be dose level 2.

Table 3 provides details of toxicity reported in more than $10 \%$ of patients of the 21 patients who received at least one dose of protocol therapy. Myelosuppression, transaminase elevation, hyperlipidemia, and electrolyte disturbance were the most commonly reported laboratory abnormalities. Mucositis and gastrointestinal symptoms were the most commonly reported symptoms. The incidence of myelosuppression did not seem to increase in subsequent cycles. Nonhematologic toxicity was uncommon in subsequent cycles of therapy, although two patients at dose level 2 had subsequent cycle DLT (grade 4 hypertriglyceridemia; grade 3 stomatitis).

Four patients did not reach goal sirolimus trough concentrations in the first 12 days of therapy. Of the 17 
Table 3: Hematologic and nonhematologic toxicities observed in 21 patients in cycle 1 and in subsequent cycles of therapy with sirolimus, topotecan, and cyclophosphamide. ${ }^{\mathrm{a}}$

\begin{tabular}{|c|c|c|c|c|c|c|c|c|}
\hline & \multicolumn{4}{|c|}{$\begin{array}{l}\text { Maximum Grade Observed per Patient } \\
\text { During Cycle } 1\end{array}$} & \multicolumn{4}{|c|}{$\begin{array}{l}\text { Maximum Grade Observed per Patient Across } \\
\text { All Subsequent Cycles (2-12) }\end{array}$} \\
\hline & G1 & G2 & G3 & \begin{tabular}{|l|} 
G4 \\
\end{tabular} & G1 & G2 & G3 & G4 \\
\hline & \multicolumn{4}{|c|}{$(\mathrm{N}=21$ patients, 21 cycles $)$} & \multicolumn{4}{|c|}{ ( $\mathrm{N}=6$ patients, 32 cycles $)$} \\
\hline \multicolumn{9}{|l|}{ Hematologic toxicity } \\
\hline Anemia & 9 & 3 & 3 & & 1 & 2 & & \\
\hline Leukopenia & 4 & 7 & 4 & 3 & 3 & 2 & 1 & \\
\hline Lymphopenia & 3 & 3 & 8 & 1 & 2 & 3 & & \\
\hline Neutropenia & 3 & 3 & 3 & 4 & 1 & 1 & 1 & 1 \\
\hline Thrombocytopenia & 3 & 2 & 6 & 3 & 2 & & & \\
\hline \multicolumn{9}{|c|}{\begin{tabular}{|l|l} 
Nonhematologic toxicity \\
\end{tabular}} \\
\hline Abdominal pain & 4 & & & & 2 & & & \\
\hline ALT elevation & 5 & 1 & & & 1 & & & \\
\hline AST elevation & 3 & 1 & & & & & & \\
\hline Anorexia & 2 & 3 & & & 1 & & & \\
\hline Bruising & 3 & & & & & & & \\
\hline Constipation & 4 & & & & 1 & & & \\
\hline Dehydraton & 2 & 1 & & & & & & \\
\hline Diarrhea & 8 & 1 & & & 3 & & & \\
\hline Dry skin & 3 & & & & & & & \\
\hline Fatigue & 6 & 2 & & & 4 & 1 & & \\
\hline Headache & 4 & 3 & & & & 1 & & \\
\hline Hypercholesterolemia & 5 & & & & 3 & & & \\
\hline Hyperglycemia & 6 & & & & 1 & & & \\
\hline Hypertension & 4 & & & & & & & \\
\hline Hypertriglyceridemia & 4 & 2 & 2 & & & & 1 & 1 \\
\hline Hypoalbuminemia & 3 & & & & & & & \\
\hline Hypokalemia & 8 & & & & 2 & & & \\
\hline Mucositis & 9 & 2 & & & & 2 & 1 & \\
\hline Nausea & 11 & 4 & & & 3 & 1 & & \\
\hline Proteinuria & 3 & 2 & & & 4 & & & \\
\hline Rash & 2 & 1 & & & 1 & & & \\
\hline Vomiting & 10 & 1 & & & 1 & 2 & & \\
\hline
\end{tabular}

${ }^{a}$ Only toxicities possibly, probably, or definitely related to therapy with sirolimus, topotecan, and cyclophosphamide and which occurred in more than $10 \%$ of patients in cycle 1 are displayed.

patients that ultimately reached sirolimus trough goal in cycle 1 , the median time to first sirolimus trough goal within range was 11 days (range, 4 to 19). In cycle 1 , the median sirolimus dose needed to achieve a trough concentration of $3-7.9 \mathrm{ng} / \mathrm{mL}$ was $1.05 \mathrm{mg} / \mathrm{m}^{2}$ (range, 1.03 to 1.83 ) and the median dose need to achieve a trough concentration of $8-12 \mathrm{ng} / \mathrm{mL}$ was $2.76 \mathrm{mg} / \mathrm{m}^{2}$ (range, 1.25 to 5.29 ).

\section{Efficacy}

One patient who withdrew one day after the first dose of protocol therapy was not evaluable for antitumor activity. No objective responses were observed among the
20 remaining patients evaluable for response. Six patients (30\%) had a best response of stable disease, including patients with alveolar soft part sarcoma (12 cycles), desmoplastic small round cell tumor (DRSCT, 11 cycles), osteosarcoma (6 cycles), Ewing sarcoma (4 cycles), esthesioneuroblastoma (3 cycles), and glioblastoma multiforme ( 2 cycles). Among the four sarcoma patients with prolonged stable disease ( $>4$ cycles), all reached sirolimus trough goal in the first 12 days of cycle 1 (median 8.5 days, range 4 to 12). At the time of this report, all patients have discontinued therapy due to disease progression.

The estimated progression-free survival (PFS) of the 20 response evaluable patients is shown in Figure 1. The median PFS was 33 days (range, 11 to 364 days). The 
Table 4: Sirolimus loading and maintenance dosing by assigned dose level, age, and weight

\begin{tabular}{|c|c|c|}
\hline & $\begin{array}{l}\text { Targeted Sirolimus Trough } \\
\text { 3-7.9 } \mathrm{ng} / \mathrm{mL}\end{array}$ & $\begin{array}{l}\text { Targeted Sirolimus Trough } \\
\text { 8-12.0 ng/mL }\end{array}$ \\
\hline $\begin{array}{l}\text { Age }<13 \text { years and } \\
\text { Weight }<40 \mathrm{~kg}\end{array}$ & $\begin{array}{l}\text { Initial loading dose: } 3 \mathrm{mg} / \mathrm{m}^{2} \text { on day } 1 \\
\text { - } \quad \text { Initial maintenance dose: } 1 \mathrm{mg} / \mathrm{m}^{2} \text { once daily } \\
\text { starting on day } 2 \text { of each cycle }\end{array}$ & $\begin{array}{l}\text { - Initial loading dose: } 3 \mathrm{mg} / \mathrm{m}^{2} \text { on day } 1 \\
\text { Initial maintenance dose: } 1 \mathrm{mg} / \mathrm{m}^{2} \text { divided } \\
\text { twice daily starting on day } 2 \text { of each cycle }\end{array}$ \\
\hline $\begin{array}{l}\text { Age }>13 \text { years or } \\
\text { Weight }>40 \mathrm{~kg}\end{array}$ & $\begin{array}{l}\text { - Initial loading dose: } 3 \mathrm{mg} \text { on day } 1 \\
\text { Initial maintenance dose: } 1 \mathrm{mg} \text { once daily } \\
\text { starting on day } 2 \text { of each cycle }\end{array}$ & $\begin{array}{l}\text { - Initial loading dose: } 6 \mathrm{mg} \text { on day } 1 \\
\text { Initial maintenance dose: } 2 \mathrm{mg} \text { once daily } \\
\text { starting on day } 2 \text { of each cycle }\end{array}$ \\
\hline
\end{tabular}

probability of PFS at 3 and 6 months was 25\% (95\% CI, 9 to 45$)$ and $15 \%(95 \% \mathrm{CI}, 4$ to 34$)$, respectively.

\section{Correlative studies}

Nineteen patients consented to the optional correlative study evaluating pharmacodynamics angiogenesis markers. Due to a range of logistical and patient issues (weekends, timing of blood draws in relation to visits to the study center, early disease progression) only thirteen samples were available at baseline and six samples were available at day 21. Over the course of cycle 1, median thrombospondin-1 decreased from 929 to 466 $\mathrm{ng} / \mathrm{mL}$, median soluble vascular endothelial growth factor receptor-2 (sVEGFR2) decreased from 11,560 to 7,569 $\mathrm{pg} / \mathrm{mL}$, median placental growth factor (PGF) decreased from 16 to $12 \mathrm{pg} / \mathrm{mL}$, and median endoglin decreased from 5 to $4 \mathrm{ng} / \mathrm{mL}$. Five patients had paired baseline and day 21 plasma samples available for statistical evaluation of potential changes in these markers (Figure 1). Thrombospondin-1 concentrations significantly decreased over cycle 1 ( $p=0.043$, Figure 2A). Soluble VEGFR2 concentrations trended downward over the course of cycle 1 , but did not reach statistical significance $(p=0.057$, Figure 2B). Endoglin and PGF levels did not significantly change over the course of cycle 1 ( $p=0.50$ and $p=0.69$, Figures $2 \mathrm{C}$ and 2D). Given the small sample size, changes in antiangiogenesis markers were not evaluated in relation to efficacy.

\section{DISCUSSION}

We have developed a new regimen that combines metronomic chemotherapy with an oral mTOR inhibitor. The MTD of oral combination therapy with sirolimus, topotecan, and cyclophosphamide in children and young

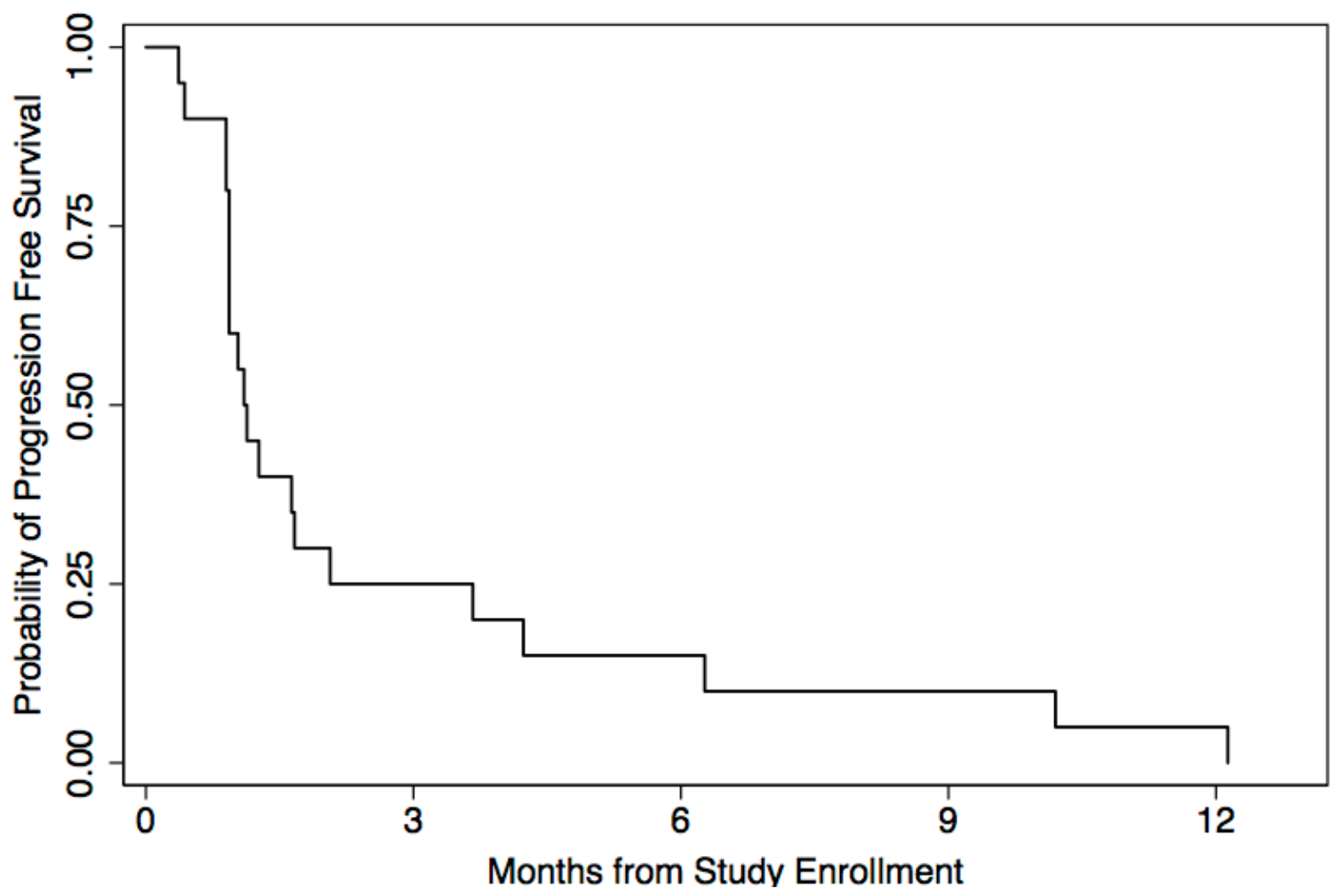

Figure 1: Kaplan-Meier estimated progression-free survival of 20 response-evaluable patients treated with sirolimus, topotecan, and cyclophosphamide therapy. 
adults with refractory and relapsed solid tumors was determined to be sirolimus on days 1-21 with steadystate trough goal concentration range of 8-12.0 ng/mL; cyclophosphamide $25 \mathrm{mg} / \mathrm{m}^{2} /$ dose on days 1-21; and topotecan $0.8 \mathrm{mg} / \mathrm{m}^{2} /$ dose on days $1-14$. This oral 3-drug regimen was well tolerated in this heavily pretreated population. No unexpected toxicities were observed. Overall, the most common toxicity was myelosuppression, which was reversible and manageable. In general, common symptoms of mucositis and gastrointestinal events, including diarrhea, nausea, and vomiting, were low-grade. There were no objective antitumor responses in this trial. Several patients with a variety of different tumors, including four patients with sarcoma subtypes, may have benefited as evidenced by stable disease for multiple cycles, though timing of disease evaluations may have over-estimated duration of disease control. Of note, one patient with stable disease for 12 months had alveolar soft part sarcoma, a histology that may show more indolent growth, making it difficult to draw firm conclusions about the role this therapy played in stabilizing her disease.

A previous phase 1 study that evaluated metronomic
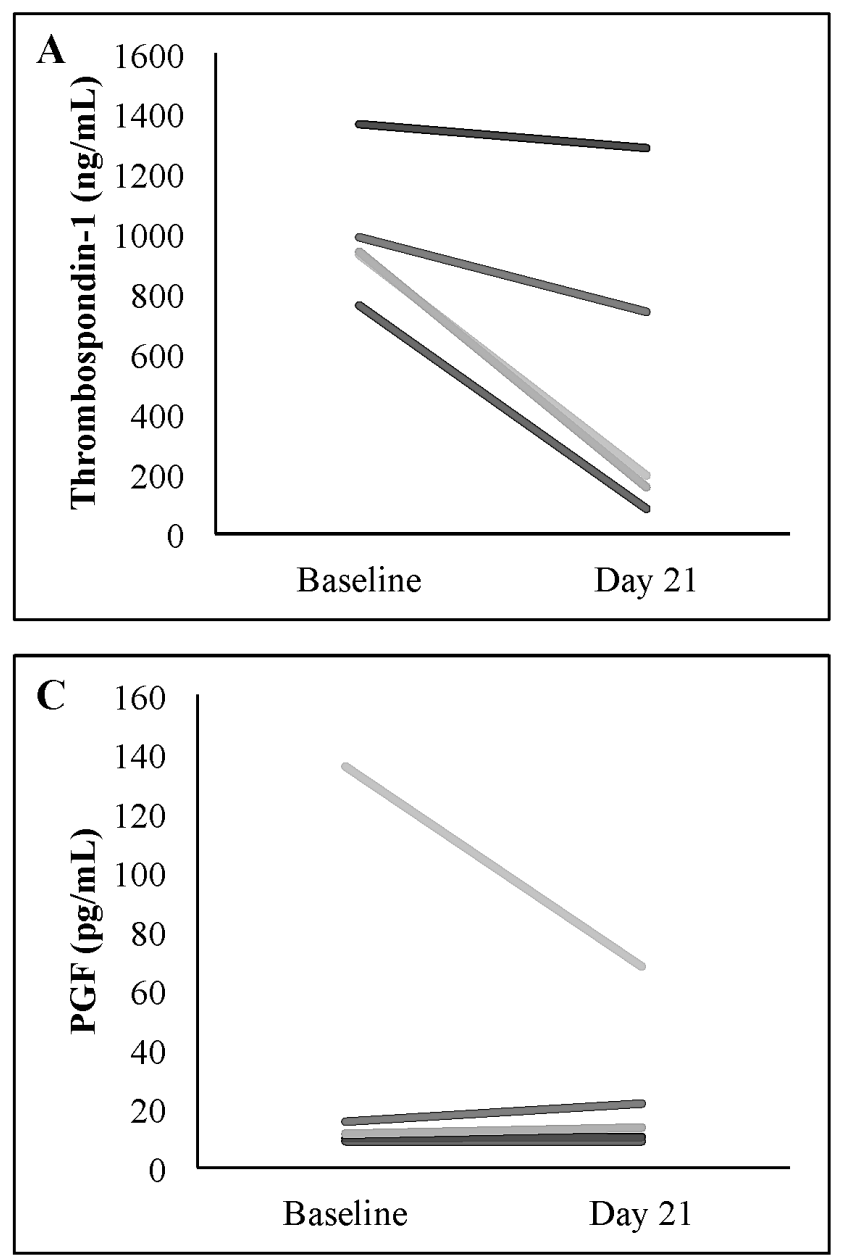

oral dosing of the combination of cyclophosphamide and topotecan in pediatric patients determined the MTD to be oral cyclophosphamide $\left(50 \mathrm{mg} / \mathrm{m}^{2} / \mathrm{dose}\right)$ and oral topotecan $\left(0.8 \mathrm{mg} / \mathrm{m}^{2} /\right.$ dose $)$ administered for 14 consecutive days in 21-28-day cycles. [18] Reversible hematologic dose-limiting toxicities (neutropenia and thrombocytopenia) were similar to those seen in this trial, [18] although the MTD of the cyclophosphamide in our trial was lower $\left(25 \mathrm{mg} / \mathrm{m}^{2} /\right.$ dose $)$, which may have been attributable to the addition of sirolimus; differences in length of administration (14 vs. 21 days on our trial); or overlap in elimination pathways between sirolimus and cyclophosphamide. While non-hematologic toxicities greater than grade 3 were not observed with metronomic cyclophosphamide and topotecan alone, the grade 3 and 4 toxicities of mucositis and hypertriglyceridemia seen in patients treated on the current study are expected toxicities of sirolimus, or other sirolimus analogues, such as temsirolimus and everolimus. [19-22] Despite the fact that the median time to reach sirolimus steady-state was 11 days, subsequent cycle DLTs were uncommon suggesting that delays in reaching steady-state in cycle
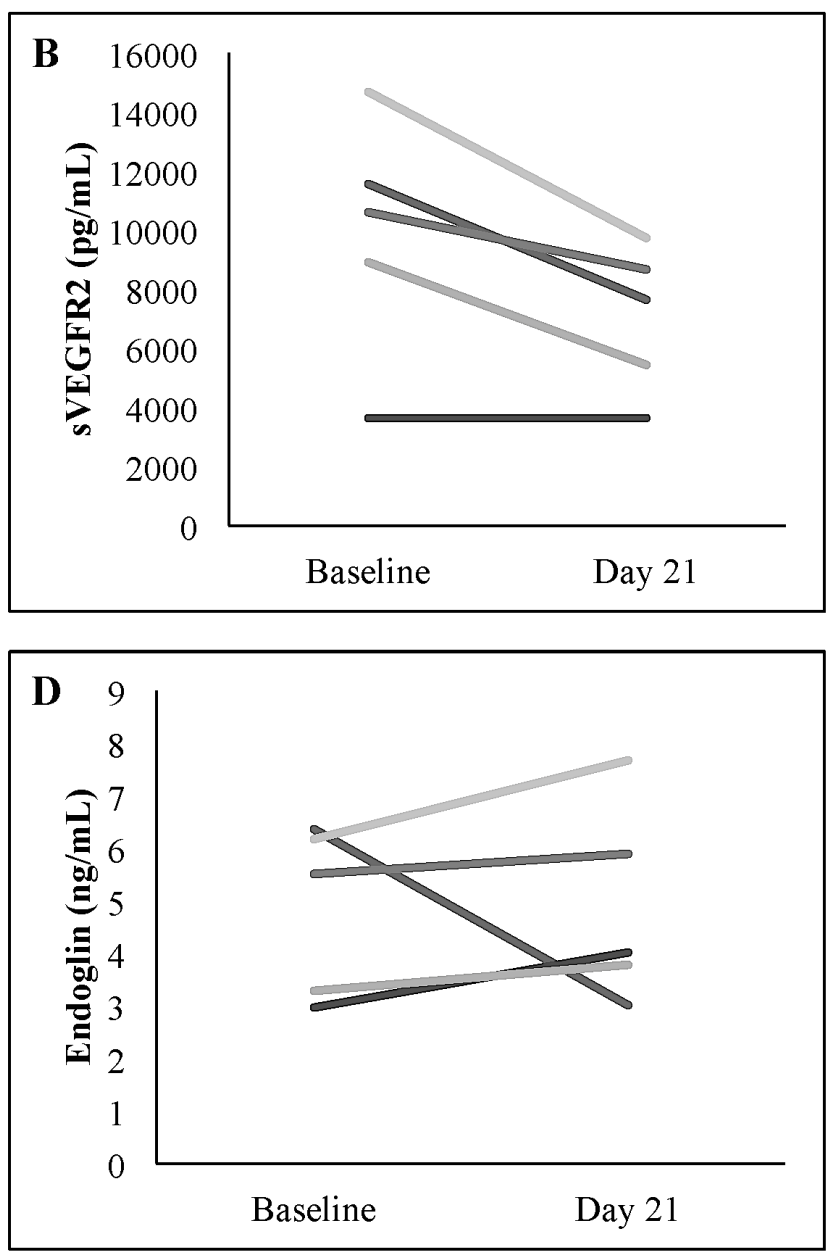

Figure 2: Changes in plasma A. thrombospondin-1, B. soluble VEGFR2 (sVEGFR2), C. placental growth factor (PGF), and D. endoglin concentrations from baseline to day $21 \pm 2$ of cycle 1 in five individual patients with paired samples. 
1 did not result in falsely concluding that a higher dose level was tolerable. While our study did not investigate other schedules of metronomic therapy, a schedule of oral cyclophosphamide and topotecan administered for 7 days every other week may have maximized drug exposure while decreasing hematologic toxicities.

In clinical trials, sirolimus has been combined with various cytotoxic chemotherapy agents, including intensive AML induction chemotherapy (mitoxantrone, etoposide, cytarabine); [23] gemcitabine; [24] vinblastine; [25] and paclitaxel. [26] Of particular interest, in a phase 2 trial of advanced sarcomas, patients received daily sirolimus (4 mg/dose) and oral cyclophosphamide (200 $\mathrm{mg}$ /dose) administered daily for 7 days every other week in 28-day cycles. Myelosuppression was a common toxicity reported with this combination. [27] Serious adverse events attributed to this therapy occurred in $11 \%$ of patients and included infection, pneumonitis, and thrombosis. [27] Patients were followed for a minimum of 6 months and $21 \%(10 / 47)$ of evaluable patients were progression-free for at least 6 months. [27] The 6-month PFS in patients receiving sirolimus and cyclophosphamide is higher than what was found in our study, which may be attributable to differences in the patient populations between the two clinical trials.

We examined correlative biomarkers in this trial to improve our understanding of the effect of this combination on angiogenesis pathways. While plasma thrombospondin, endoglin, PGF, and soluble VEGFR2 levels have been used as angiogenesis biomarkers in many previous studies of VEGF receptor tyrosine kinase (RTK) inhibitors, [28] little work has evaluated these markers in patients receiving mTOR inhibitors and/or metronomic chemotherapy. As in previous studies with RTK inhibitors, our combination therapy resulted in decreases in soluble VEGFR2 concentrations. [28] In addition, our study showed a significant decrease in thrombospondin-1 concentration, similar to an adult study of metronomic cyclophosphamide in advanced malignancies. [29, 30] Thrombospondin-1 is a modulator of angiogenesis and is hypothesized to play a role in mediating angiogenic activity of metronomic chemotherapy. [31] Previous studies of metronomic chemotherapy in pediatric patients showed that an elevated baseline thrombospondin-1 concentration may correlate with clinical benefit. [32, 33] Our sample size precluded a similar analysis in this study. We did not detect changes in PGF and endoglin in this study. The clinical significance of these changes in potential surrogate markers requires further evaluation.

One limitation of our study was difficulty in reaching sirolimus goal steady-state concentrations in a timely manner. Four out of 21 patients (19\%) were deemed inevaluable for cycle 1 DLT assessment due to delays in reaching sirolimus goal trough concentrations by day 12 of treatment. This experience has been reported by other groups. For example, Morgenstern and colleagues reported difficulty in achieving target sirolimus trough concentration in the range of $10-15 \mathrm{ng} / \mathrm{mL}$ in pediatric patients treated with sirolimus and vinblastine. [25] In their study, sirolimus trough levels were monitored weekly during the first cycle and then at the start of subsequent cycles once in target range. Overall, only 10 of 14 patients achieved the target concentration after a mean of 3 weeks (range, 1 to 8 weeks). [25] Of all measured sirolimus concentrations, $27 \%$ were within the target range, whereas $14 \%$ were $>15 \mathrm{ng} / \mathrm{mL}$ and $59 \%$ were $<10$ $\mathrm{ng} / \mathrm{mL}$. [25] This considerable inter-patient variability in dose-concentration relationship is consistent with previous reports of the variable pharmacokinetics of sirolimus. [34] Likewise in the current study, we observed a wide range of sirolimus doses needed to achieve the desired trough concentrations. These findings suggest that newer sirolimus analogues ("rapalogues") with more consistent pharmacokinetic properties might be better suited in the context of a study targeting specific trough concentrations.

In conclusion, the combination of oral sirolimus, topotecan, and cyclophosphamide was well tolerated in this heavily pre-treated population. However, in the context of this phase 1 study, it is unclear if the addition of sirolimus improved on the anti-tumor effect of metronomic cyclophosphamide and topotecan which previously demonstrated some activity against recurrent pediatric solid tumors (partial response in one patient with neuroblastoma and a patient with medulloblastoma with prolonged stable disease). [18] The convenience associated with oral administration, evidence of modulation of angiogenesis pathways, and our findings of several patients with prolonged stable disease suggest that this regimen may be considered for patients with advanced sarcoma seeking a palliative regimen.

\section{MATERIALS AND METHODS}

\section{Patients}

Patients were eligible for participation if they were 12 months to 30 years of age, had histologic diagnosis of solid tumor (including brain tumors) with measurable or evaluable disease, and had no known curative options. Patients were required to have a Karnofsky (age $>16$ years) or Lansky (age $<16$ years) performance score of 50 or more and to have recovered from previous therapy. Patients previously treated with sirolimus, topotecan, or cyclophosphamide as single agents were eligible. Patients previously treated with two of the three drugs were eligible, though patients previously treated with all three agents in combination were excluded. Patients previously treated with sirolimus analogues (e.g. temsirolimus, everolimus, or ridaforolimus) were also eligible. Patients were required to have adequate baseline bone marrow 
(absolute neutrophil count $>750 / \mu \mathrm{L}$; platelet count $>$ $75,000 / \mu \mathrm{L}$ for patients without bone marrow involvement or platelet count $>25,000 / \mu \mathrm{L}$ for those with known bone marrow metastatic disease), renal, hepatic, pulmonary, and central nervous system function according to defined protocol criteria. Patients were required to have serum fasting triglyceride and cholesterol levels both $<300 \mathrm{mg}$ / dL.

Exclusion criteria included: pregnancy or breastfeeding; concurrent use of strong CYP3A4 inducers or inhibitors; concurrent use of enzyme-inducing anticonvulsants; concurrent use of corticosteroids not on a stable or decreasing dose for 7 days prior to enrollment; uncontrolled infections; or history of allergic reaction to compounds of similar composition to sirolimus, topotecan, or cyclophosphamide.

The protocol was approved by the University of California, San Francisco Committee on Human Research. Written informed consent (and assent when applicable) was obtained for all patients. This trial was registered with ClinicalTrials.gov number NCT01670175.

\section{Treatment and evaluations}

The dose escalation schema is summarized in Table 2. Patients received daily oral sirolimus and cyclophosphamide on days 1-21 in a 28-day cycle. This was combined with oral topotecan given once daily on days 1-14. Sirolimus dosing was based on steady-state plasma trough concentrations with a starting goal level of 3-7.9 ng/mL in dose level 1 and goals levels of 8-12.0 ng/ $\mathrm{mL}$ in subsequent dose levels. The topotecan dose was 0.8 $\mathrm{mg} / \mathrm{m}^{2} /$ dose in all dose levels. The cyclophosphamide dose was $25 \mathrm{mg} / \mathrm{m}^{2} /$ dose for dose levels 1 and 2 and $50 \mathrm{mg} / \mathrm{m}^{2} /$ dose in dose level 3. Calculations for body surface area were capped at $2 \mathrm{~m}^{2}$ for cyclophosphamide and topotecan. Initial sirolimus loading and maintenance doses were based on the patient's weight, age, and assigned dose level (Table 4). Of note, sirolimus is available commercially as an oral solution $(1 \mathrm{mg} / \mathrm{mL})$ and in tablet form $(1 \mathrm{mg}$ and $2 \mathrm{mg}$ tablets). Both formulations were available for study subjects and were chosen at the discretion of the treating physician. Sirolimus trough levels were drawn 3-4 days following a loading dose. If the level was in the desired range, a repeat level was drawn 3-4 days following the initial level. Once a stable level within the goal range was obtained two times in a row, levels were obtained once per cycle unless a change in concomitant medication or liver function had the potential to impact sirolimus metabolism. Adjustments to sirolimus maintenance and loading doses were based on calculations provided in the package insert. [35] Patients without disease progression or unacceptable toxicity could receive up to two years of therapy.

Patients had routine physical examinations and surveillance laboratory testing to evaluate for toxicity. Toxicities were graded according to the National Cancer
Institute (NCI) Common Terminology Criteria, version 4.0. DLT was defined as any of the following that were attributed as at least possibly related to study therapy: grade 4 neutropenia with fever or grade 4 neutropenia for $>7$ days; platelet transfusion for a platelet count $<10 \mathrm{x}$ $10^{9} / \mathrm{L}$ or for clinical bleeding on 2 separate days within a 7 day period; myelosuppression that delayed start of subsequent cycle by $>14$ days; any grade 3 or 4 nonhematological toxicity with the specific exclusion of grade 3 nausea and vomiting $<3$ days, grade 3 diarrhea $<3$ days, grade 3 mucositis or stomatitis $<3$ days, grade 3 alanine/ aspartate aminotransferase (ALT/AST) that returned to grade $<1$ or baseline prior to the start of the next treatment cycle, grade 3 fever, grade 3 infection, grade 3 electrolyte abnormalities responsive to oral supplementation within 7 days, grade 3 or 4 hypertriglyceridemia that returned to grade $<2$ within 7 days of drug interruption, grade 3 or 4 hypercholesterolemia responsive to lipid lowering medication within 35 days, and grade 3 hyperglycemia that returned to $<$ grade 2 or baseline prior to start of next treatment cycle.

Patients underwent disease evaluation at baseline and then at the end of cycles 1 and 3, and then every third cycle. For patients with measurable disease, tumor response was evaluated by RECIST. [36] For patients with neuroblastoma, a modification of the International Neuroblastoma Response Criteria was used that utilized meta-iodobenzylguanidine (MIBG) response by Curie score and RECIST for soft tissue disease. [37, 38]

\section{Biomarker studies}

Plasma was obtained at baseline and day $21 \pm$ 2 of cycle 1 in consenting patients to assess the impact of study therapy on biomarkers of angiogenesis. Thrombospondin-1, endoglin, PGF, and sVEGFR2 levels were measured by ELISA using commercially available kits (R\&D Systems, Minneapolis, MN).

\section{Dose escalation strategy and statistical methods}

The primary endpoint for determining dose escalation was DLT attributed to study therapy in cycle 1. A standard $3+3$ phase 1 dose escalation design was utilized, with escalation starting at dose level 1. Patients were considered evaluable for dose escalation decisions if: they (1) received $>17$ of the 21 of the planned doses of sirolimus and cyclophosphamide AND (2) received $>11$ of the 14 of the planned doses of topotecan AND were followed until they met toxicity criteria to proceed to cycle 2 . In addition, patients who experienced DLT at any time after the first doses of medication were considered evaluable. Lastly, patients must have had at least one sirolimus trough level in goal range within the first 12 days of cycle 1 to be considered evaluable for dose escalation/ 
de-escalation purposes at that dose level.

Changes in angiogenesis biomarkers obtained at baseline and at the end of cycle 1 were assessed using Wilcoxon signed rank test for all paired data available at baseline and day $21 \pm 2$. PFS was defined as the time from enrollment to first occurrence of disease progression or death. Patients without an event were censored at the time of last patient contact. We estimated PFS with the Kaplan-Meier method and reported the median PFS and PFS at 3 and 6 months for the treatment group. All statistical analyses were performed using Stata, version 13 (StataCorp, College Station, TX).

\section{CONFLICTS OF INTEREST}

None.

\section{GRANT SUPPORT}

Supported in part by the Alex's Lemonade Stand Foundation (KTV, KKM, SGD), Global Giving Foundation (KKM), Frank A. Campini Foundation (KTV, WCG, KKM, SGD), Hyundai Hope on Wheels (SGD), the UCSF Helen Diller Family Comprehensive Cancer Center (SGD), and the Mildred V. Strouss Chair (KKM). The contents are solely the responsibility of the authors and do not necessarily represent the official views of the funding sources listed above.

\section{REFERENCES}

1. Borders EB, Bivona $\mathrm{C}$ and Medina PJ. Mammalian target of rapamycin: biological function and target for novel anticancer agents. Am J Health Syst Pharm. 2010; 67:20952106.

2. Brown RE, Tan D, Taylor JS, Miller M, Prichard JW and Kott MM. Morphoproteomic confirmation of constitutively activated mTOR, ERK, and NF-kappaB pathways in high risk neuro-blastoma, with cell cycle and protein analyte correlates. Ann Clin Lab Sci. 2007; 37:141-147.

3. Zenali MJ, Zhang PL, Bendel AE and Brown RE. Morphoproteomic confirmation of constitutively activated mTOR, ERK, and NF-kappaB pathways in Ewing family of tumors. Ann Clin Lab Sci. 2009; 39:160-166.

4. Mateo-Lozano S, Tirado OM and Notario V. Rapamycin induces the fusion-type independent downregulation of the EWS/FLI-1 proteins and inhibits Ewing's sarcoma cell proliferation. Oncogene. 2003; 22:9282-9287.

5. Mateo-Lozano S, Gokhale PC, Soldatenkov VA, Dritschilo A, Tirado OM and Notario V. Combined transcriptional and translational targeting of EWS/FLI-1 in Ewing's sarcoma. Clin Cancer Res. 2006; 12:6781-6790.

6. Houghton PJ, Morton CL, Kolb EA, Gorlick R, Lock R, Carol H, Reynolds CP, Maris JM, Keir ST, Billups CA and Smith MA. Initial testing (stage 1) of the mTOR inhibitor rapamycin by the pediatric preclinical testing program. Pediatr Blood Cancer. 2008; 50:799-805.

7. Johnsen JI, Segerstrom L, Orrego A, Elfman L, Henriksson M, Kagedal B, Eksborg S, Sveinbjornsson B and Kogner P. Inhibitors of mammalian target of rapamycin downregulate MYCN protein expression and inhibit neuroblastoma growth in vitro and in vivo. Oncogene. 2008; 27:29102922.

8. Houghton PJ, Morton CL, Gorlick R, Lock RB, Carol H, Reynolds CP, Kang MH, Maris JM, Keir ST, Kolb EA, Wu J, Wozniak AW, Billups CA, Rubinstein L and Smith MA. Stage 2 combination testing of rapamycin with cytotoxic agents by the Pediatric Preclinical Testing Program. Mol Cancer Ther. 2010; 9:101-112.

9. Mascarenhas L, Meyer WH, Lyden E, Rodeberg DA, Indelicato DJ, Linardic CM, Anderson JR and Hawkins DS. Randomized phase II trial of bevacizumab and temsirolimus in combination with vinorelbine $(\mathrm{V})$ and cyclophosphamide (C) for first relapse/disease progression of rhabdomyosarcoma (RMS): A report from the Children's Oncology Group (COG). J Clin Oncol. 2014; 32:suppl; abstr 10003 .

10. Semela D, Piguet AC, Kolev M, Schmitter K, Hlushchuk R, Djonov V, Stoupis C and Dufour JF. Vascular remodeling and antitumoral effects of mTOR inhibition in a rat model of hepatocellular carcinoma. J Hepatol. 2007; 46:840-848.

11. Guba M, von Breitenbuch P, Steinbauer M, Koehl G, Flegel S, Hornung M, Bruns CJ, Zuelke C, Farkas S, Anthuber M, Jauch KW and Geissler EK. Rapamycin inhibits primary and metastatic tumor growth by antiangiogenesis: involvement of vascular endothelial growth factor. Nat Med. 2002; 8:128-135.

12. Saylors RL, 3rd, Stine KC, Sullivan J, Kepner JL, Wall DA, Bernstein ML, Harris MB, Hayashi R, Vietti TJ and Pediatric Oncology G. Cyclophosphamide plus topotecan in children with recurrent or refractory solid tumors: a Pediatric Oncology Group phase II study. J Clin Oncol. 2001; 19:3463-3469.

13. Walterhouse DO, Lyden ER, Breitfeld PP, Qualman SJ, Wharam MD and Meyer WH. Efficacy of topotecan and cyclophosphamide given in a phase II window trial in children with newly diagnosed metastatic rhabdomyosarcoma: a Children's Oncology Group study. J Clin Oncol. 2004; 22:1398-1403.

14. Bernstein ML, Devidas M, Lafreniere D, Souid AK, Meyers PA, Gebhardt M, Stine K, Nicholas R, Perlman EJ, Dubowy R, Wainer IW, Dickman PS, Link MP, et al. Intensive therapy with growth factor support for patients with Ewing tumor metastatic at diagnosis: Pediatric Oncology Group/ Children's Cancer Group Phase II Study 9457-a report from the Children's Oncology Group. J Clin Oncol. 2006; 24:152-159.

15. Hunold A, Weddeling N, Paulussen M, Ranft A, Liebscher $\mathrm{C}$ and Jurgens H. Topotecan and cyclophosphamide in patients with refractory or relapsed Ewing tumors. Pediatr 
Blood Cancer. 2006; 47:795-800.

16. London WB, Frantz CN, Campbell LA, Seeger RC, Brumback BA, Cohn SL, Matthay KK, Castleberry RP and Diller L. Phase II randomized comparison of topotecan plus cyclophosphamide versus topotecan alone in children with recurrent or refractory neuroblastoma: a Children's Oncology Group study. J Clin Oncol. 2010; 28:3808-3815.

17. Kerbel RS and Kamen BA. The anti-angiogenic basis of metronomic chemotherapy. Nat Rev Cancer. 2004; 4:423436.

18. Bowers DC, Aquino VM, Leavey PJ, Bash RO, Journeycake JM, Tomlinson G, Mulne AF, Haynes HJ and Winick NJ. Phase I study of oral cyclophosphamide and oral topotecan for children with recurrent or refractory solid tumors. Pediatr Blood Cancer. 2004; 42:93-98.

19. Jimenez-Rivera C, Avitzur Y, Fecteau AH, Jones N, Grant $\mathrm{D}$ and $\mathrm{Ng}$ VL. Sirolimus for pediatric liver transplant recipients with post-transplant lymphoproliferative disease and hepatoblastoma. Pediatr Transplant. 2004; 8:243-248.

20. Lobach NE, Pollock-Barziv SM, West LJ and Dipchand AI. Sirolimus immunosuppression in pediatric heart transplant recipients: a single-center experience. J Heart Lung Transplant. 2005; 24:184-189.

21. Fouladi M, Laningham F, Wu J, O’Shaughnessy MA, Molina K, Broniscer A, Spunt SL, Luckett I, Stewart CF, Houghton PJ, Gilbertson RJ and Furman WL. Phase I study of everolimus in pediatric patients with refractory solid tumors. J Clin Oncol. 2007; 25:4806-4812.

22. Geoerger B, Kieran MW, Grupp S, Perek D, Clancy J, Krygowski M, Ananthakrishnan R, Boni JP, Berkenblit A and Spunt SL. Phase II trial of temsirolimus in children with high-grade glioma, neuroblastoma and rhabdomyosarcoma. Eur J Cancer. 2012; 48:253-262.

23. Perl AE, Kasner MT, Tsai DE, Vogl DT, Loren AW, Schuster SJ, Porter DL, Stadtmauer EA, Goldstein SC, Frey NV, Nasta SD, Hexner EO, Dierov JK, et al. A phase I study of the mammalian target of rapamycin inhibitor sirolimus and MEC chemotherapy in relapsed and refractory acute myelogenous leukemia. Clin Cancer Res. 2009; 15:67326739.

24. Martin-Liberal J, Gil-Martin M, Sainz-Jaspeado M, Gonzalo N, Rigo R, Colom H, Munoz C, Tirado OM and Garcia del Muro X. Phase I study and preclinical efficacy evaluation of the mTOR inhibitor sirolimus plus gemcitabine in patients with advanced solid tumours. Br J Cancer. 2014; 111:858865.

25. Morgenstern DA, Marzouki M, Bartels U, Irwin MS, Sholler GL, Gammon J, Yankanah R, Wu B, Samson Y and Baruchel S. Phase I study of vinblastine and sirolimus in pediatric patients with recurrent or refractory solid tumors. Pediatr Blood Cancer. 2014; 61:128-133.

26. Abu-Khalaf MM, Baumgart MA, Gettinger SN, Doddamane I, Tuck DP, Hou S, Chen N, Sullivan C, Lezon-Geyda K, Zelterman D, Hatzis C, Deshpande H, Digiovanna MP,
Azodi M, Schwartz PE and Harris LN. Phase 1b study of the mammalian target of rapamycin inhibitor sirolimus in combination with nanoparticle albumin-bound paclitaxel in patients with advanced solid tumors. Cancer. 2015; 121:1817-1826.

27. Schuetze SM, Zhao L, Chugh R, Thomas DG, Lucas DR, Metko G, Zalupski MM and Baker LH. Results of a phase II study of sirolimus and cyclophosphamide in patients with advanced sarcoma. Eur J Cancer. 2012; 48:1347-1353.

28. Baruchel S, Wu B, Mokhtari RB, Glade Bender JL, DuBois SG, Widemann BC, Park JR, Stempak D, Ahern CH and Weigel B. Surrogate biomarkers of antiangiogenesis in Children's Oncology Group (COG) phase I trials. J Clin Oncol. 2011; 29:suppl; abstr 9502.

29. Lansiaux A, Salingue S, Dewitte A, Clisant S and Penel N. Circulating thrombospondin 1 level as a surrogate marker in patients receiving cyclophosphamide-based metronomic chemotherapy. Invest New Drugs. 2012; 30:403-404.

30. Penel N, Clisant S, Dansin E, Desauw C, Degardin M, Mortier L, Vanhuyse M, Bonodeau F, Fournier C, Cazin $\mathrm{JL}$ and Adenis A. Megestrol acetate versus metronomic cyclophosphamide in patients having exhausted all effective therapies under standard care. Br J Cancer. 2010; 102:12071212.

31. Bocci G, Francia G, Man S, Lawler J and Kerbel RS. Thrombospondin 1, a mediator of the antiangiogenic effects of low-dose metronomic chemotherapy. Proc Natl Acad Sci U S A. 2003; 100:12917-12922.

32. Robison NJ, Campigotto F, Chi SN, Manley PE, Turner CD, Zimmerman MA, Chordas CA, Werger AM, Allen JC, Goldman S, Rubin JB, Isakoff MS, Pan WJ, et al. A phase II trial of a multi-agent oral antiangiogenic (metronomic) regimen in children with recurrent or progressive cancer. Pediatr Blood Cancer. 2014; 61:636-642.

33. Kieran MW, Turner CD, Rubin JB, Chi SN, Zimmerman MA, Chordas C, Klement G, Laforme A, Gordon A, Thomas A, Neuberg D, Browder T and Folkman J. A feasibility trial of antiangiogenic (metronomic) chemotherapy in pediatric patients with recurrent or progressive cancer. J Pediatr Hematol Oncol. 2005; 27:573-581.

34. Schubert M, Venkataramanan R, Holt DW, Shaw LM, McGhee W, Reyes J, Webber S and Sindhi R. Pharmacokinetics of sirolimus and tacrolimus in pediatric transplant patients. Am J Transplant. 2004; 4:767-773.

35. Anonymous. (2011). Package information: Rapamune (sirolimus) oral solution and tablets: Pfizer).

36. Eisenhauer EA, Therasse P, Bogaerts J, Schwartz LH, Sargent D, Ford R, Dancey J, Arbuck S, Gwyther S, Mooney M, Rubinstein L, Shankar L, Dodd L, Kaplan R, Lacombe D and Verweij J. New response evaluation criteria in solid tumours: revised RECIST guideline (version 1.1). Eur J Cancer. 2009; 45:228-247.

37. Ady N, Zucker JM, Asselain B, Edeline V, Bonnin F, Michon J, Gongora R and Manil L. A new 123I-MIBG 
whole body scan scoring method-application to the prediction of the response of metastases to induction chemotherapy in stage IV neuroblastoma. Eur J Cancer. 1995; 31A:256-261.

38. Brodeur GM, Pritchard J, Berthold F, Carlsen NL, Castel V, Castelberry RP, De Bernardi B, Evans AE, Favrot M, Hedborg $\mathrm{F}$ and et al. Revisions of the international criteria for neuroblastoma diagnosis, staging, and response to treatment. J Clin Oncol. 1993; 11:1466-1477. 